tuberculosas. Análisis de 112 casos. Rev Méd Chile 1961; 89: 3-8.

12.- Kraljevic O R, Borgoño J M. Tratamiento de las septicemias. Rev Méd Chile 1961: 293-7.

13.- Kraljevic O R, Paredes L, Philippi F, Borgoño J M. Nuevas penicilinas. Mesa Redonda. Coordinador: R. Valdivieso. Rev Méd Chile 1964; 91: 338-52.
14.- Borgoño J M, Pearson E. Fiebre tifoidea y paratifoidea. Análisis clínico y de laboratorio de un brote estacional. Rev Méd Chile 1965; 93: 145-51.

15.- Salcedo M, Borgoño J M, Greber R, Lobos H, Hazbun M, Solari G. Tratamiento de la fiebre tifoidea y paratifus con trimetoprim y sulfametoxazol. Rev Méd
Chile 1972; 100: 1064-7.

16.- Borgoño J M. Meningitis purulenta: un problema de siempre. Rev Méd Chile 1993; 121: 199-200.

17.- Borgoño J M. Sarampión: pasado, presente y futuro. Rev Chil Infect 1997; 14: 71-3.

18.- Borgoño J M. Vacuna antivariólica. Rev Chil Infect 2002; 19: 60-2.

\title{
Relato
}

\section{Harina de otro costal}

\author{
Bruno Bisconti*
}

Vittorio Capra, a quien todos llamaban Vito, había decidido esa mañana después de diez años de arduo trabajo, abandonar el hospital que tanto amaba y que lo había formado como pediatra. Atrás quedarían los grandes maestros, las reuniones clínicas de los casos de difícil diagnóstico, los turnos de Navidad y Año Nuevo, las carreras por las escaleras para asistir a un niño en paro cardiorrespiratorio y los amigos de tantas jornadas. La reunión habitual del "Servicio de Infecciosos" de los días viernes había terminado, y supo en ese instante que ésta sería su última reunión. Su camino debía continuar lejos de la capital, a pesar de haber logrado posicionarse como un respetado y digno integrante de la familia hospitalaria del más prestigioso hospital pediátrico de su país.

Desde la terraza del cuarto piso, transformada en sala de reuniones, miraba impávido el avance de la negra nube que comenzaba a cubrir el cielo de la gran ciudad como un manto amenazante que inevitable-

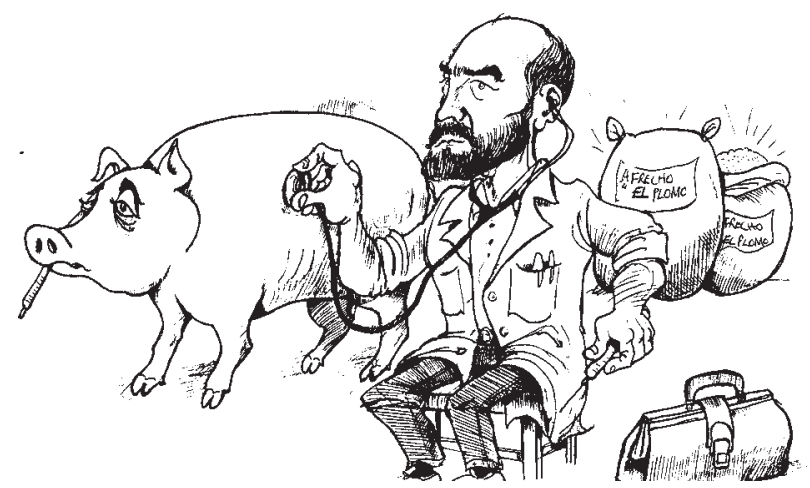

para enfrentar los nuevos desafíos, y abordar los problemas, por difíciles que estos fueran. No sólo contaba con el respaldo de sus conocimientos, sino también con el apoyo incondicional de los viejos amigos y de toda su familia.

A las seis de la tarde cerró la puerta de su oficina dejando en su interior las sonrisas de cientos de niños que lo habían conocido, y se llevó en el alma sus tiernas miradas. Se despidió de su secretaria que lo había acompañado por años, y quedó flotando en el ambiente el eco de sus últimas palabras.

- Adiós doctor, que le vaya bien y venga a verme.

No era el momento para sentimentalismos. En sus hombros pesaba la decisión que había tomado y sabía que éste era un camino sin retorno. $\mathrm{Se}$ dirigió a la notaría de Don Joaquín Vega donde lo esperaba el Dr. Guglielmo Centofuochi. Subió las escaleras con paso firme y después de leer el documento de compraventa estampó su firma, sellando así la firme decisión de migrar. Res- 
piró profundo, y con un fuerte apretón de manos se despidieron cariñosamente. Su mujer lo esperaba en casa con sus tres hijos y, al llegar, se dispusieron a cenar. Ellos ignoraban lo sucedido, sin embargo, percibieron el ambiente más tenso que lo habitual.

Era agosto y ya había anochecido. La fría noche fue calando todos los rincones de la casa y arropó a los niños en sus camas más temprano que de costumbre. Entonces, Vito y María Lucía, su mujer, se encontraron en un abrazo sin decir palabra. Vito debía ser fuerte y no mostrar debilidad ante ella, sin embargo, la decisión que había tomado era de tal trascendencia y la tensión de aquel día había sido tan intensa, que habían terminado por derribar las fuerzas de este hombre. Comenzó a llorar y sus lágrimas cayeron sobre su hombro. María Lucía se mantuvo fuerte, lo abrazó, acarició su pelo y por largos minutos se fundieron en ese abrazo amalgamando sus cuerpos en uno solo, una sola alma. Finalmente, ella interrumpió el silencio.

$$
\text { - Te amo. }
$$

Ella presentía lo que había ocurrido y comprendía lo difícil que había sido aquel día. Secó sus lágrimas con sus suaves manos y Vito experimentó un alivio.

- Vendiste la oficina, ¿verdad?

- Si - contestó Vito, como dejando caer una gota en un cristal.

- Ya no hay vuelta atrás, pero tengo mucha fe y optimismo que nos irá bien; juntos, siempre estaremos bien.

Vito sintió en sus palabras el apoyo que lo reafirmó en su decisión.

La llegada al nuevo hospital no fue fácil. Muchos veían en él a un médico que, avalado por sus antecedentes, les plantearía una fuerte competencia, lo cual estaba lejos de ser su objetivo. Sólo lo animaba el interés por contribuir a desarrollar la pediatría en un hospital de provincia. El tiempo se encargó de despejar el sinnúmero de interrogantes y temores que se plantearon a su llegada.

Caminando por los pasillos del viejo hospital, Vito percibió que algo había ocurrido que inquietaba a médicos y enfermeras. Dos hermanos habían ingresado el día anterior con un severo estado de mal nutrición y provenían de un pueblo cordillerano llamado El Calvario. La historia no había comen- zado ayer, sino muchos meses antes, cuando Rosa Antiquina había llevado en repetidas ocasiones a sus hijos al consultorio rural sin observar mejoría. La intuición de madre la hizo buscar ayuda en el hospital de su sector, distante treinta kilómetros de su modesta casa de campo. Ellos padecían de dolores musculares y enflaquecían día a día, lo que hizo sospechar a quienes la atendieron la posibilidad de maltrato infantil. El caso de Rosa Antiquina dejó de inquietar a los médicos quienes endosaron el problema a la asistente social para que hiciera la visita al hogar y estampara la denuncia de maltrato infantil ante el tribunal de menores.

La visita no alcanzó a realizarse porque esa tarde los niños habían enfermado aún más. Rosa Ester, la hija de nueve años, ya no podía caminar, y Roberto, de siete, acusaba fuertes dolores abdominales y serias dificultades en la marcha. Rosa Ester no sólo dejó de caminar; se fue apagando lentamente como un cirio al viento y se sumergió en un sueño profundo que obligó a los médicos a trasladarla a la UCI pediátrica. Vito, al ver el hemograma con una severa anemia y un punteado basófilo en los glóbulos rojos, sospechó una intoxicación por plomo. Rosa Ester se debatía entre la vida y la muerte. Ahora dependía de un ventilador mecánico para que su corazón continuara latiendo. El nivel de plomo en sangre era determinante para confirmar el diagnóstico. Todos corrían: los teléfonos no dejaban de sonar, el centro toxicológico se movilizaba para obtener los antídotos, el director del hospital autorizó el envío urgente de la muestra al laboratorio de la capital y veinticuatro horas más tarde llegaba el resultado.

¡Maldición, carajo! Los niveles de plomo eran tan altos que rebasaban toda posibilidad de éxito en aquella gesta. Vito comenzó la terapia, pero Rosa Ester ya volaba por otros mundos, tanto o más lejanos que la distancia entre El Calvario y el Paraíso.

Rosa Antiquina permanecía al lado de su hija, inmersa en un mundo extraño y adverso, lleno de máquinas y sonidos que parecían tan disonantes como una sinfonía dodecafónica que golpeaba sus oídos. Lejos de agradarla, le trasmitían una inmensa angustia, sin entender qué estaba sucediendo y por qué había sucedido. Lloraba en silencio y en su rostro se habían aguzado los estigmas de su dura y sacrificada vida. Vito se mantuvo alejado unos instantes respetando la intimidad de esa cadencia dramática, y sus palabras no lograron armonizar el réquiem que oscurecía la atmósfera.

Comprendió así, que los pobres tienen una fortaleza mayor para enfrentar la muerte, porque desde que nacen cuentan con ella. Para ellos, la vida está tan cerca de la muerte como la muerte tan cerca de la vida eterna.

Roberto tuvo mejor suerte. Se trató y volvió a su hogar con serias dificultades para caminar. Seis meses después, Vito lo vio sonreír por primera vez cuando asomó por el largo pasillo de la mano de su madre. Al verlo, ella se detuvo y Roberto continuó caminando. Ahora ya podía caminar sin la ayuda de las órtesis que habían sostenido sus pies todos estos meses. Su alegría era tan grande y hermosa como un glaciar sempiterno. Quería demostrarle a su doctor y al mundo que ahora era capaz de pararse solo y caminar, sin ayuda de nada ni de nadie; que podría valerse por si mismo y ser independiente. Cuando llegó a su lado, Vito lo saludó y se inclinó para besarlo. En sus ojos se trasparentaba una mirada de cristalina inocencia y gratitud. Rosa Antiquina lo contemplaba desde lejos y se acercó sigilosamente.

- Dígale a su doctor lo que le quería decir..., pues...

La timidez de Roberto hizo que los segundos se perfilaran cansados y se prolongaran en una agonía extemporánea. Vito lo acogió, y acariciando su pelo quiso aliviar las grandes dificultades del menor y trató de liberarlo de lo que su madre le pedía. Roberto, indeciso, lo miró, pero le pareció tan alto e inalcanzable que, abandonando sus ojos en el infinito, dejó escapar un bisbiseo.

\section{- Gracias.}

Vito le sonrió.

- Veo que ahora puedes caminar solo, eh. ¿Cómo estás, bien?

- Bien.

- ¿Qué bueno!. Ahora podrás correr, saltar y jugar como antes, ¿si?

- Sí.

Roberto lo miraba con una sonrisa turgente de incredulidad, pero ausente.

Vito, impactado por el daño, no le dijo que su capacidad intelectual estaba dañada seria y definitivamente, y que continuaría 
siendo pobre por toda su vida; la peor de las pobrezas: la de cuerpo y alma.

A Vito le inquietaba saber cuál era el origen de esta intoxicación y, una vez terminado el tratamiento de los niños, se dispuso a investigar. En forma paralela, el Departamento de Salud Ambiental inició su propia investigación. El doctor se desplazó hasta la casa de Rosa Antiquina y allí pudo conocer mejor a su marido.

Raimundo Hualquivir, con quien había tenido pocas oportunidades de conversar en el hospital, era un hombre de campo, más bien retraído y de pocas palabras. Sin embargo, al verlo llegar a su hogar se mostró diferente y se esmeró en atenderlo. Le ofreció mote con huesillos para pasar el calor y lo invitó a sentarse..., y conversaron a la sombra de un parrón. El ambiente era distendido y la calma del mediodía se reflejaba en el rostro de Raimundo que no mostraba signos de tensión ni amargura. Quizás no había aprendido a expresar desde pequeño sus emociones, y por ende, la pena que lo embargaba. Nada hacía sospechar que diez días antes, su hija Rosa Ester había muerto. Él, más que nadie, se mostraba locuaz e interesado en saber qué había sucedido.

¿Por qué ocurría este hecho insólito que mantenía preocupado a todos los habitantes del lugar, si nada había cambiado en los trece últimos años? La casa era la misma y no había sido pintada; el agua que bebían provenía del pozo que habían utilizado siempre; el molino en el que molían el trigo era el que por años los proveía de harina para hacer el pan de cada día y los utensilios que utilizaban para comer estaban viejos y gastados por el paso de los años. No había nada que tuviera plomo, ni siquiera la vieja batería abandonada en el patio, de la cual sólo quedaba la carcasa.

Rosa María, la hija menor de casi tres años, estaba absorta en su juego de cocina preparando el té en una vieja cocinilla oxidada, y en su fantasía creaba deliciosos pasteles y pancitos de barro. Para ella nada había cambiado. Su pequeño mundo crecía cuando se empinaba en los zapatos con taco de su madre, pero todo seguía igual cuando correteaba descalza las gallinas en el patio, día tras día. A su corta edad no podía comprender por qué había visto llorar a su ma- dre, y la ausencia de Rosa Ester no cambiaba mucho su entorno.

Mientras conversaban, ella corrió hacia su padre para llevarle una tacita de té barroso que traía en una taza de plástico rosado, ignorando absolutamente al hombre sentado a su lado. No sabía que al doctor le interesaba también saber si en ella circulaba el mortífero elemento químico. Vito no encontró nada sospechoso de una posible fuente de intoxicación. Después de haber recorrido todos los rincones de la casa y el patio, divisó un cerdo flaco acostado en su chiquero que se alimentaba con afrecho. Se despidió y les prometió volver a tomar muestras de sangre al grupo familiar y también a los abuelos que vivían a tres kilómetros más al sur.

Esta vez volvió provisto de jeringas y acompañado de su amigo Santos Cortés, un médico veterinario, que más tenía de santo que de cortés. Era un hombre bueno desde el alma. No pasaba desapercibido. Con su gran simpatía rápidamente conquistaba a la gente, pero su franqueza y su lenguaje destemplado, muchas veces le jugaban en contra despertando sentimientos encontrados, siendo querido por muchos y odiado por otros. Conocía el campo como la palma de su mano. Cuando Vito lo invitó a El Calvario se alegró de poder visitar a doña Carmela, la casera que lo proveía de queso de cabra. Partieron entusiasmados una hermosa mañana de domingo. Los esperaban Raimundo y su familia para someterse resignadamente a la toma de muestra.

— ¿Quiúo Iñor! — saludó Santos.

Era un saludo entre familiar y respetuoso - acostumbrado a tratar con gente de campo. Rápidamente se tramaron en conversaciones campestres. Al ver el cerdo, reparó en su estado de desnutrición y el aspecto poco saludable del animal.

- Oiga Iñor, ¿y este chancho lo está criando pa' engorda o pa' hacer sopa 'e hueso?, porque así como está, no pasa del próximo invierno.

- No..., si estaba gordito, pero desde que le empecé a dar afrecho me paré' que las costillas le jueron asomando. Por hacerla mejor... ¿Tendrá eso que llaman carásito? ¿Que piensa usté?

- Yo no pienso na' Iñor. Lo noto harto a mal traer, y lo veo más pa' la otra que pa' ésta. Qué carásito, cara 'e fiambre le estoy hallando.

Raimundo quedó más desconcertado con la franqueza del veterinario.

Santos le sugirió a su amigo que le tomaran una muestra de sangre al cerdo también.

Vito estaba excitado porque nunca había trabajado con animales y envidiaba la habilidad de su amigo para entrar rápidamente en confianza. Después de tomar la muestra al cerdo fueron a visitar a los abuelos quienes, estando en antecedentes de la visita médica, los esperaban en el remanso del mediodía.

Don Recaredo, un hombre bajo, pero de anchas espaldas, descansaba bajo el alero del corredor y doña Jacinta humedecía el piso de tierra salpicando agua con un jarro para refrescar el ambiente. Al verlos llegar, interrumpió su faena y atentamente acudieron a su encuentro.

- Buenas tardes caballero- saludó Doña Jacinta, ¿cómo le va? - dijo Don Recaredo.

- Bien, muy bien, algo acalorado solamente- exclamó Vito.

- Tomen asiento, asientito caballeroofrecía Doña Jacinta, mientras Don Recaredo acercaba unas sillas de mimbre.

- ¿Se servirian un motecito? — preguntó Doña Jacinta.

- Pero ipor supuesto!, dijeron los doctores al unísono.

El mote con huesillos reposaba en un jarro sobre una mesita de mimbre. Doña Jacinta corrió en su busca y luego se acercó trayendo una bandeja con el jarro y unos vasos. Ella era gordita y muy simpática.

- El mote está güenazo y lo hice reciencito con ceniza 'e hualle. Sírvanse los doctores pa' pasar la calor, miren que está fresquecito - ofreció doña Jacinta.

- Gracias, muchas gracias. ¡Qué calor! ¿no? Hace tres meses que no cae una gota de agua, por lo menos - agregó Santos.

- Efectivamente, usté lo ha dicho- confirmó Don Recaredo.

Después de servirse, Vito sacó sus jeringas y comenzó a trabajar, pero tuvo serios problemas para encontrar la vena de doña Jacinta.

- Oiga doctor..., paré' que usté no le pega na' mucho a la custión de enfermería. 
- Calma doña Jacinta, que con paciencia se llega al cielo.

- Sí, pero yo no quiero na' irme toavía pa' allá, pus caballero - se rió relajadamente.

Vito no sólo sudaba por el calor, sino además porque la maldita vena se le rompió y tuvo que pincharle el otro brazo. Esta vez salvó su honra y salió airoso.

Con todas las muestra tomadas, Vito se preguntaba con qué nombre enviarían la muestra de un cerdo al Instituto de Sanidad Pública. Santos ni siquiera se había cuestionado el hecho de enviar una muestra de sangre animal a un instituto que trabaja con muestras humanas. Ya la había bautizado con el nombre de Carlos, y por apellido, el nombre de su raza. Carlos Landras sería entonces un pariente lejano de la familia.

Antes de irse, Raimundo les comentó que él salía de madrugada de su casa y debía caminar cinco kilómetros para llegar al Fundo El Porvenir donde trabajaba como obrero agrícola.

Que ironía - pensó Vito el porvenir de la pobreza que asolaba y desgarraba las almas de las familias campesinas.

Se llevaba dos panes recién amasados para apaciguar el hambre, y trabajaba hasta caída la tarde. Él había comenzado a notar que a poco andar los dolores en las piernas le impedían mantener el ritmo de la caminata y, a menudo, debía detenerse. Así, los dolores menguaban. Su ignorancia le hizo pensar que ya no era el mismo y que los años le estaban pasando la cuenta.

¡En Andorra quedó la zorra!-exclamó Vito al conocer los resultados. Los niveles de plomo eran tan altos que el cielo se ennegreció y se vino la tormenta: todos intoxicados, incluido Don Carlos Landras.

¿Qué había en común en ellos, que viviendo en lugares alejados destilaban plomo hasta por los poros? ¿Por qué Raimundo tenía los niveles más altos si pasaba todo el día fuera de la casa?, preguntas que Vito no pudo responder.

La investigación del Departamento de Salud Ambiental no había podido aclarar todavía estas interrogantes. Las muestras de agua de distintos alimentos - incluida la harina - y de pintura de la casa, no contenían plomo. La incertidumbre crecía.

- Dicen que la niña se durmió y no despertó nunca más — se comentaba en el pueblo.
El plomo, que había dormido con ellos quién sabe cuánto tiempo, ahora los despertaba para mantener vivo el interés de todos aquellos que, asustados, todavía permanecían despiertos.

Vito reparó en un hecho que podría contribuir a aclarar las cosas. Había notado que el cerdo estaba flaco, que era alimentado con afrecho y estaba intoxicado. Entonces - pensó - la fuente de plomo podría ser harina contaminada. Sin embargo, el análisis había sido negativo. Volvió a la casa de Raimundo quien le explicó que la cosecha de trigo del año pasado había sido peor que la de años anteriores y la harina se había acabado hacía tres semanas, por lo cual compró un quintal en el supermercado de la ciudad.

La hipótesis de la harina contaminada quedó dando vueltas en la cabeza de Raimundo como un molino de viento que no paró de girar hasta cuando terminó su cosecha de trigo, lo llevó a moler, envió una muestra de harina al Departamento de Salud Ambiental, y dos días después el análisis reveló altísimos niveles de contaminación con plomo. El molino se detuvo y se esfumó en el viento.

¡Agárrate, Raimundo, que vamos a galopar! —exclamó, Vito — cuando vislumbró el problema que se le venía encima, y rió nerviosamente. Él imaginó que todos los pequeños agricultores del lugar hacían lo mismo que Raimundo, por lo cual supuso que los intoxicados ya no eran una familia, sino cientos de familias del lugar. No se equivocó. El molino tenía casi cien años y había sido reparado hacía poco tiempo. Cuando inspeccionaron las piedras que hacían la molienda, estaban fracturadas y cada una de las fracturas había sido rellenada con plomo. Interrogado el dueño del molino, alegaba absoluta inocencia porque no sabía que el plomo pudiera ser tan dañino para la salud; y además — dijo - no es la primera vez que lo hemos hecho - como queriendo reafirmarse en su posición. El molino fue clausurado temporalmente mientras las piedras eran cambiadas por otras nuevas, y pudo seguir funcionando con la anuencia de las autoridades de salud. Afortunadamente, el molino tenía un libro de registro de las personas que enviaban su trigo a moler $\mathrm{y}$, de este modo se estimó el número de posibles intoxi- cados. La cifra alcanzaba a dos mil quinientas personas.

Este gigantesco problema de salud pública pondría a prueba a todo el sistema de salud del Estado. Se iniciaron las reuniones y la pesada maquinaria comenzó a moverse en forma lenta y titubeante como un enfermo convaleciente. Cada cuál pretendía obtener dividendos que beneficiara su imagen ante la comunidad. Sin embargo, quedó en evidencia la poca capacidad de resolución de las autoridades quienes, de una u otra manera, contribuyeron con su burocracia a que el problema no encontrara una rápida y oportuna solución. Arbitrariamente determinaron que sólo tratarían a los más afectados. El Estado eludió su responsabilidad; nunca otorgó los recursos necesarios para actuar con rapidez y eficacia y sólo se pudo tratar un diez por ciento de los intoxicados, cinco meses después de ocurrida la muerte de Rosa Ester, cuando el daño era irreparable. Una vez más los pobres fueron discriminados. Los niños habían disminuido definitivamente su capacidad intelectual en un treinta por ciento. Así concluía una triste historia en El Calvario, un perdido pueblo cordillerano del sur del país.

En repetidas oportunidades las autoridades de salud instaron al Dr. Capra a publicar en alguna revista médica esta intoxicación. La importancia de difundir lo ocurrido - dado que no se tenían registros de una intoxicación masiva por plomo de origen alimentarioy aparecer como autores de un trabajo, les encumbraba el ego más allá de la más elemental capacidad de autocrítica, convencidos de que lo habían hecho fantástico. Vito se recostó bajo la sombra del silencio y se durmió en el crepúsculo acariciado por el viento que le arrebató su pena, su rabia y su vergüenza.

Al despertar sintió la necesidad de evaluar la capacidad intelectual de los niños intoxicados para medir el daño $\mathrm{y}$, de acuerdo a los resultados, presentar los antecedentes para postularlos a una pensión de invalidez. Junto a un grupo de psicólogos diseñaron un protocolo de trabajo. Para poder aplicarlo era necesario disponer de recursos que les permitieran solventar los gastos de traslado y alimentación de los niños. Comenzó a buscar formas de financiamiento, y se dirigió a la Gobernación. 
Como Gobernador, Ricardo Bianco dedicaba gran parte de su tiempo a las labores políticas encomendadas por el gobierno o su partido - el Partido Democrático Popular. Nadie sabía cuáles eran y en qué se traducían.

Era miope. Con lentes veía poco más allá de su nariz, y sin ellos, nada. Era una miopía central, no periférica. Además, padecía un defecto visual que le negaba una visión nítida. Estos graves problemas lo limitaban en sus aspiraciones políticas. Había desarrollado una estrategia que le daba buenos dividendos. Cuando conversaba, estaba más preocupado de saludar a cualquier "bulto" que pasara por su lado que de su interlocutor, lo que le permitía mantener su popularidad. Era bueno para las matemáticas; muchas veces saludaba dos veces a la misma persona, lo que resultaba gracioso y multiplicaba la simpatía en la gente. Además, poseía un tremendo olfato político. Era capaz de detectar a kilómetros de distancia cualquier evento social que terminara en un cóctel o comida. Allí se sentía a sus anchas para proyectar su carrera política y seguir escalando. Su máxima aspiración era escalar el cerro San Cristóbal, con la ayuda del funicular, por supuesto, para evitar apunarse. Ahí era uno más del zoológico político, probablemente dentro de la especie de los primates.

Para Vito, Bianco no era santo de su devoción, ni menos un santo al cual prenderle una vela; le conocía tantas historias que cada vez que entraba a la catedral, la Virgen fruncía el seño y los santos se despertaban de su sueño eterno. Jesucristo estaba tan ocupado con los problemas de la humanidad que su presencia no lograba distraerlo. A su salida, el cielo le lloraba las penas de los pobres, pero premunido de botas, impermeable y paraguas, no se mojaba.

La Gobernación para el Pueblo es como la monarquía europea. Todos saben que existe, pero nadie sabe para qué sirve, aparte de adornar la personalidad arquitectónica y urbanística de la ciudad. Consciente de todo ello, Vito estaba bastante escéptico con su visita, pero como en pedir no hay engaño y no hay peor diligencia que la que no se hace, partió ilusionado.

Bianco lo recibió amablemente y conversaron de lo divino y lo humano. Cuando Vito le explicó lo sucedido y el daño causado a la salud de la gente, él se mostró receptivo. Según le manifestó, algo había escuchado en las noticias que había habido algunos intoxicados con plomo en un sector de la provincia, pero que él no conocía. Hasta ahí llegaba su preocupación por el tema: estaba informado. Vito insistía en la necesidad de evaluar el daño para poder indemnizar a esta población de inocentes.

— Sí, —acotaba el Gobernador- ¿y cuántos son?

- Dos mil quinientos.

- ¿Dos mil quinientos?, qué increíble, hombre. ¿Qué interesante!

Vito quiso percibir que su petición estaba siendo bien acogida por el Gobernador. De improviso, y en forma absolutamente inesperada, tuvo una expresión que lo condenaría a las penas del infierno, definitivamente.

- Oye, pero... esta gente, con plomo o sin plomo, da lo mismo ¿no es cierto?

Tal fue el remezón de Vito que ni un terremoto lo habría sacudido tanto en su silla. Quiso no creer lo que había oído. Pensó haber escuchado mal, pero el repentino silencio en la sala no permitió dudar de lo que había dicho. No podía entender que la máxima autoridad en la provincia no tuviera la más mínima conciencia social y ni siquiera esbozara un atisbo de preocupación por la salud de esos pobres seres humanos. Sólo le interesaba saber cuántos eran para sacar cálculos de posibles votantes en su próxima campaña política.

El silenció congeló las palabras, se apoderó del pánico en la cara de Bianco y se transformó en un ruido subterráneo que anunciaba un nuevo terremoto. Capra se aferró a los brazos de la silla y cambió bruscamente de expresión. De sus ojos brotaban chispas de furia que si hubieran alcanzado al Gobernador, lo habrían fulgurado en forma instantánea. Bianco, que dimensionó la gravedad de sus palabras, y percibiendo la dureza en el rostro de Capra, se levantó ágilmente para tratar de revertir lo dicho, pero mientras más hablaba, más se hundía en su propia miseria..., y el aire se enrareció.

Vito se paró y lo miró seria y fijamente a los ojos.

- No tenemos nada más de qué hablar. ¡Hueles a miseria!

Se dio media vuelta y él trató de detenerlo, pero le fue imposible. Ya caminaba deci- dido hacia la puerta de salida. Bajó las escaleras, y al llegar a la calle vio a dos jóvenes enamorados que se besaban sin importarles el mundo a su alrededor. Se detuvo a contemplarlos y luego se marchó, diciendo:

Señor,

Sólo los enamorados pueden abstraerse en su mundo,

Porque de ese amor fecundo

Nacerá un mundo mejor.

Un año después, Ricardo Bianco dejó la Gobernación para trabajar en su campaña política como candidato a Diputado. Su asesor le organizaba su agenda y tenía considerado visitar El Calvario como un lugar importante dentro del calendario de actividades. Mencionar allí lo ocurrido con el plomo sería una estrategia que le depararía una gran cantidad de votos. Organizó una visita, donde sostendría un encuentro con los principales dirigentes comunales y la gente del pueblo. $\mathrm{Su}$ asesor tenía todo dispuesto y la gente lo esperaba con ansias porque nunca los había visitado una autoridad. A su llegada todos querían saludarlo, y los niños se le acercaban para tocarlo y conocer a su futuro diputado. A las mujeres las saludaba de beso y a los hombres les daba la mano. El punto de encuentro era el estadio de fútbol. Todos se sentaron en las graderías y él les dirigió unas palabras.

\section{Amigas y amigos:}

He venido a visitarlos hoy, porque siempre habia querido conocer esta maravillosa tierra y su hermosa gente. Ustedes son los hombres y mujeres que hacen grande este pais, porque en vuestras manos está depositado el futuro de nuestra patria. Gente sacrificada, gente trabajadora, gente inteligente como ustedes es lo que necesita este país para seguir creciendo. Me siento verdaderamente honrado con vuestra presencia y orgulloso de encontrarme entre todos ustedes. He venido a compartir y conocer cuáles son sus aspiraciones, cuáles son vuestras necesidades, cuáles son sus grandes anhelos y cuáles son los problemas que los aquejan. Estos son los momentos en los cuales uno puede empaparse de lo que el pueblo está sintiendo y quiere, empaparse de lo que el pueblo clama. Pero 
no siempre es posible que vuestras ideas y vuestros problemas sean escuchados en el gobierno, porque ustedes necesitan un diputado que los represente en el parlamento, un diputado que sea el portavoz de vuestras inquietudes para que vuestros problemas sean resueltos. Sé que esta tierra fue duramente golpeada, hace algunos años, cuando muchos de ustedes sufrieron una intoxicación por plomo. Sé cuánto perjuicio ha causado el plomo en vuestra salud y en estos hermosos niños, hijos todos de la patria. Sé que aquí no se ha hecho justicia, porque el daño no ha sido reparado. Yo me pregunto ¿Qué hicieron los médicos cuando tuvieron que enfrentar este grave problema? ¿Qué hizo el Gobierno para acudir en vuestra ayuda? Es precisamente, en estos momentos dificiles, que los verdaderos hombres con vocación de servicio público $y$ comprometidos con el pueblo se hacen presente. ¿Y dónde estaban todos ellos? Esta situación no debe volver a repetirse. Vuestros hijos tienen el justo derecho a tener una buena educación y acceso a la salud oportuna y eficiente. Cuando yo sea diputado mejoraré la educación, la salud y lucharé para que todos tengan un trabajo digno y bien remunerado en El Calvario. Pero la primera medida que impulsaré, y ténganlo por seguro, trabajaré incansablemente hasta obtener del Gobierno una indemnización y una pensión para todos los intoxicados de este pueblo, que les asegure un bienestar, porque lo considero justo y ustedes se lo merecen.

- iBravo, bravo! - gritaba la multitud y aplaudía entusiastamente. ¡Viva Bianco,
Bianco viva! - continuó gritando la gente del pueblo.

Los dirigentes comunales se le acercaron y lo invitaron a pasar al salón para conversar más tranquilos y en privado. La gente se fue a sus casas convencida que ahora todos sus problemas tendrían solución.

El día de las elecciones, Bianco se levantó optimista y alegre. Sabía que había hecho una buena campaña y confiaba en el triunfo. En la tarde, los resultados lo daban como vencedor por un estrecho margen, sólo dos mil quinientos votos.

Los años pasaron y en El Calvario la vida continuó igual. Nunca más se oyó hablar del Diputado Bianco y nunca más, alguien lo vio.

Los niños intoxicados sí vieron frustradas sus esperanzas de tocar el cielo con una flor. ¡Porca miseria!. 